WINPEC Working Paper Series No.E1505

June 2015

Effects of social network structure on the diffusion and adoption of agricultural technology: Evidence from rural Ethiopia

Yasuyuki Todo, Petr Matous, Dagne Mojo

Waseda INstitute of Political EConomy

Waseda University

Tokyo,Japan 


\title{
Effects of social network structure on the diffusion and adoption of agricultural technology: Evidence from rural Ethiopia*
}

\author{
Yasuyuki Todo $^{\mathrm{a}}$ \\ Petr Matous ${ }^{\mathrm{b}}$ \\ Dagne Mojo ${ }^{\mathrm{C}}$
}

\begin{abstract}
This paper investigates the effects of social network structure on the diffusion of agricultural technologies using household-level panel data from Ethiopia. We correct for possible biases due to the endogeneity of social networks using a social experiment in which we provide mobile phones to randomly selected households. We find that the effect of social networks varies depending on the network structure and characteristics of the technologies considered. The diffusion of information on a simple technology is determined by whether farmers know an agricultural extension agent. However, the diffusion of information on a more complex technology is not promoted by simply knowing an extension agent but by knowing an agent that a particular household can rely on and by clustered networks in which most friends of the household are friends of each other. This finding suggests that knowing and understanding more complex technologies require strong external ties and flows of the same information from multiple sources.
\end{abstract}

Keywords: knowledge diffusion, technology adoption, agriculture, social network, Ethiopia

JEL classification codes: O13, O33, Q16

\footnotetext{
* The authors would like to thank Tadesse Sefera Gela, other enumerators, and the Forum for Environment Asella for their great effort in collecting household-level data; Tolessa Debele, Toshiro Mado, Kiyoshi Shiratori, Hideki Watanabe, Solomon Gelalcha Woyessa, and Terefe Degefa for their helpful suggestions regarding the household survey; and Masahisa Fujita, Stein Holden, Yukichi Mano, Tomoya Mori, Kentaro Nakajima, Keijiro Otsuka, Yasuyuki Sawada, Shumpeter Tamada, Takashi Yamano, Chikako Yamauchi, and the seminar participants at the Applied Regional Science Conference, Center for the Studies of African Economies, FASID/GRIPS, Kyoto University, and the University of Tokyo for their helpful comments on an earlier version of this paper. Todo thanks the Japan Society for the Promotion of Science, the Alliance for Global Sustainability, and Heiwa Nakajima Foundation for their financial support. The opinions expressed and arguments employed in this paper are the sole responsibility of the authors and do not necessarily reflect those of the Ethiopian Institute of Agricultural Research or any institutions with which the authors are affiliated.

${ }^{a}$ Corresponding author. Faculty of Political Science and Economics, Waseda University. 1-6-1 Nishi-Waseda, Shinjuku-ku, Tokyo, 169-8050, Japan, Email: yastodo@waseda.jp.

${ }^{\mathrm{b}}$ Complex Systems Research Group, School of Engineering, University of Sydney. Email: pmatous@gmail.com.

${ }^{c}$ Holetta Agricultural Research Center, Ethiopian Institute of Agricultural Research, Holetta, Ethiopia. Email: dagnemojo@yahoo.com.au.
} 


\section{Introduction}

Technological progress is the ultimate source of long-term economic growth (Romer, 1990), and the differences in technology levels among countries account for most of the differences in per capita income (Caselli, 2005). In the case of less developed countries (LDCs) where agriculture is the dominant sector, productivity growth in agriculture through the adoption of new technologies should play a major role in income growth.

A principal determinant of the adoption of agricultural technologies in LDCs found in existing studies on development economics is social learning from neighbors (Foster and Rosenzweig, 2010). Foster and Rosenzweig (1995) investigate the adoption of high-yielding varieties (HYVs) in India and find a positive effect of neighbors' experience, as measured by the average of their cumulative number of parcels using HYVs, on HYV cultivation. They conclude that this positive effect is evidence of learning from neighbors. Conley and Udry (2010) employ a more direct measure of knowledge flows from others. By asking farmers whether they have gone to each of seven randomly chosen farmers in the same village for advice about farming, Conley and Udry (2010) can identify informational links between farmers and find evidence of social learning through these links: when neighbors improve their yield by adjusting their level of fertilizer use, farmers exchanging information with the successful neighbors tend to imitate the adjustment.

However, social learning is not always observed in existing studies. For example, Munshi (2004) uses a method similar to that of Foster and Rosenzweig (1995) and finds evidence of social learning in the adoption of HYVs of wheat in India but not in the case of rice. Duflo et al. (2004) find that the friends and neighbors of farmers who are randomly selected and provided information on chemical fertilizer did not use more chemical fertilizer than the friends and neighbors of control farmers with no access to the information. In addition, Bandiera and Rasul (2006) find that the extent of social networks, measured by the number of adopters among relatives and friends, has a positive effect on sunflower production in Mozambique when the number of adopters is small but that the effect is negative when there are already many adopters.

In addition to economists, natural scientists and sociologists are also interested in social networks, and many have examined network structure and its effect on diffusion. Notably, Watts and Strogatz 
(1998) find that in "small-world" networks, in which most nodes are connected to each other by only a few steps, diffusion, e.g., the spread of infectious diseases, is more rapid than in other networks. A related argument is provided by Burt (1992), who emphasizes that external ties or "bridging ties" that bridge otherwise separate networks promote information flows and thus innovation.

However, based on the results of a social experiment in which he creates an online health forum, Centola (2010) claims that this promotion of information flow in "small-world" networks is not the case for the adoption of human behaviors. He finds that "clustered” networks, in which an individual's friends are generally also friends with each other, facilitate individual adoption of health behaviors to a greater extent than small-world networks. Centola argues that this result is because behavioral adoption differs from spread of diseases and requires reinforcement from multiple sources.

Another related issue discussed in the network literature is the strength of ties. Strong ties, for example, ties between individuals who interact frequently or ties with mutual trust, might promote more information and knowledge flow than weak ties. However, Granovetter (1973) finds that when people search for a job, they rely more on weak ties than on strong ties, where the strength of ties is measured by the frequency of meetings. This result may be because weak ties are more likely to be bridging ties and thus more useful in accessing diverse sources of information. However, strong ties and bridging ties may not be substitutes but rather complements. Indeed, Tiwana (2008) and Rost (2011) find that the coexistence of strong ties and bridging ties contributes to innovation.

Thus, the mixed results in development economics on whether social learning and social networks affect the adoption of new agricultural technologies may be the result of variations in the effect across network characteristics. Following this line of the literature, this paper investigates how different types of networks affect the diffusion of agricultural technologies using household-level panel data from rural Ethiopia. In particular, we contribute to the literature in the following respects.

First, we distinguish between the diffusion of information and the diffusion of practice (i.e., adoption). In this manner, we can examine which stages of the diffusion process are affected by social networks. For example, Centola (2010) argues that reinforcement from multiple sources is necessary for the adoption of behaviors, suggesting that social networks matter in the last stage of adoption but not in the information diffusion stage. Rogers (1995) also claims that mass media and official sources 
are more important in creating awareness of knowledge on a given subject but that ties to peers are more important in changing behavior.

Second, to examine how the structures of social networks affect the diffusion of information and practice, we examine the role of clustered networks. An index of the size of the personal network of each household is defined as the number of instances where a household knows at least one person bearing a name from a randomly selected list of 14. In addition, an index of the level of clustering in each household's personal network is defined as the number of pairs of the household's acquaintances who know each other among 14 randomly selected pairs of its acquaintances. Using the two social network structure indices, we test whether the size of personal networks and their level of clustering affect the diffusion of information and practices. Although Centola (2010) has observed a positive effect of clustering on the adoption of health behaviors in an online forum, results from offline networks or LDCs have yet to be obtained.

Third, we also investigate the effect of external ties. In our case, where farmers rarely have ties with people outside their home village, the most important external tie is that with agricultural extension agents who promote new agricultural technologies that researchers have developed for the region.

Fourth, we examine whether the strength of ties influences the effect of networks. The strength of ties is measured by how frequently the household head meets the network partner or whether s/he believes the partner will be willing to lend her/him money. The effects of different tie strengths have not been fully examined in the literature on agricultural knowledge diffusion in LDCs mentioned above.

Finally and importantly, we correct for possible biases due to the endogeneity of social networks using a social experiment in which we provide mobile phones to randomly selected households. As the use of mobile phones generated exogenous changes in social networks in the survey area, whether the household received a mobile phone during the experiment can be used as an instrument for the social network variables.

Our findings emphasize that the effect of social networks varies depending on their structure and the characteristics of the technologies considered. The diffusion of information on a simple technique 
examined in this study, i.e., row planting, is primarily determined by whether farmers have any external ties with an agricultural extension agent in the same village. Social networks with relatives or friends do not promote the diffusion of information diffusion on row planting regardless of the level of clustering. In addition, stronger ties with extension agents do not necessarily have a larger effect on the diffusion of information on row planting than weaker ties. These findings suggest that the diffusion of simple technologies is promoted simply by having ties to the external world, as is the case in the spread of infectious diseases (Watts and Strogatz, 1998).

However, the diffusion of information on a more complicated technology, i.e., compost, is not promoted by simply knowing an extension agent but rather by knowing a reliable agent from whom the household head believes s/he can borrow money. In other words, strong ties are necessary for the diffusion of more complex technologies. In addition, farmers are more likely to know how to implement composing when their personal network is clustered, i.e., when their friends know each other. The positive effect of network clustering is consistent with the results of Centola (2010); however, one notable difference between our results and those of Centola is that we find that reinforcement from multiple sources is necessary during the information diffusion stage, whereas Centola (2010) finds that it is necessary for practice diffusion. The similarity and difference highlight that in the case of the adoption of agricultural knowledge in LDCs, becoming aware of and understanding complex technologies require strong external ties and flows of the same information from multiple sources. Another important finding is that although social networks are important determinants of information diffusion, they do not influence practice diffusion conditional on knowing the information.

The remainder of the paper is organized as follows. Section 2 provides an overview of agriculture in Ethiopia and the six agricultural technologies examined in this study. Section 3 describes the data. Section 4 explains the empirical methodologies and results. Section 5 concludes. 


\section{Agriculture in Ethiopia}

\subsection{Systems of innovation and the extension of agricultural technologies in Ethiopia}

The largest agricultural research institution in Ethiopia is the Ethiopian Institute of Agricultural Research (EIAR), which is part of the Ministry of Agriculture and Rural Development of the Ethiopian government. EIAR has many divisions, or research centers, in different agro-ecologies of the country, each of which has large experimental plots and engages in the development of agricultural technologies and techniques suitable to the local area and entire country. Researchers at the research centers are often highly educated: most of them hold a bachelor's degree in agriculture or related fields; some hold a master's degree or even a Ph.D. The area examined in this study also has a research center, Kulumsa Research Center, located 1-2 hours by car from the households surveyed.

New technologies and techniques developed in the research centers are disseminated to farmers through the following two channels. First, the research centers directly teach new technologies and techniques to a limited number of pilot farmers in fields outside of their experimental plots. Second, the research centers teach new technologies to agricultural extension agents, called "development agents,” and the extension agents teach them to farmers at extension centers located in rural villages. Each village has three extension agents, and thus, there are approximately 50,000 agents in Ethiopia, forming a widespread extension system. Most extension agents are agricultural specialists, having completed a three-year technical vocational education program in agriculture. Extension agents live locally, provide formal training to farmers in extension centers, and visit farmers regularly to provide advice. Therefore, dissemination through extension agents may be a major channel for the diffusion of new agricultural technologies in Ethiopia.

\subsection{Technologies examined}

In this study, we focus on two particular agricultural technologies/techniques. The first is row planting, a simple technique in which farmers plant crops in rows. In the case of wheat, which is the most common agricultural product in the area, extension agents instruct to farmers that the width between rows should be approximately $20 \mathrm{~cm}$. Row planting has several advantages over broadcasting, 
namely, crops planted in appropriately spaced rows can absorb more sunlight and fresh air and farmers can weed and harvest more efficiently. As a result, row planting increases crop yields substantially, and implementing row planting requires no specific equipment or material but some additional labor. Surprisingly, row planting had not been employed in the survey area until very recently. Extension agents began to promote it in 2011, and since then, it has rapidly become widespread, as we will discuss in the next section.

The second technology is compost, or organic material, such as animal dung and crop residue, that has been fermented and decomposed for use as a fertilizer and soil amendment. The use of farmyard compost is part of organic farming, or a type of agriculture that promotes the use of renewable resources and management of biological cycles to enhance biological diversity (Eicher, 2003). Because land degradation is severe in Ethiopia, agricultural researchers have recently paid considerable attention to resource-conserving agriculture, including composting (FAO, 2008). In addition to its environmental benefits, the use of compost directly benefits poor households for two reasons. First, manure/compost increases crop production substantially (by 13\%, according to Pender and Gebremedhin (2006)). Second, compost is less costly and more widely available than chemical fertilizer, as cattle are commonly kept for farming and supplying meat and milk in Ethiopia (Pretty et al., 2006). Therefore, EIAR, its research centers, and agricultural extension agents have recently promoted compost as a key technology.

According to the local agricultural extension agents, creating nutritious compost involves several steps. First, farmers have to store animal dung with other materials, such as ash, animal feed leftovers, and crop residue, in a hole in the ground. Then, farmers should transfer the materials to another hole after three weeks to ensure that the materials are mixed with sufficient oxygen. After another three weeks, farmers have to transfer the materials to yet another hole. Farmers are instructed not to use meat, bones, fish scraps, oil, fatty materials, or dairy products as compost materials and not to exclusively use animal dung without mixing it with other appropriate materials. 


\section{Data}

\subsection{Description of the household survey}

Our household survey was conducted in Arsi Zone, Ethiopia. Zones are split into smaller administrative units, or districts, called "woredas" in the local language, and districts are further subdivided into villages, or "kebeles." We chose Tiyo District for the survey because of our professional contacts with its agricultural research center. This district produces many types of crops, including wheat, barley, fababeans, maize, and potatoes. This district is composed of 18 villages, stretching over three agro-ecologies: high- (altitude over 2,700 m), mid- (approximately 2,300 m), and low-altitude villages (below 1,800 m). As the altitude, which determines the agro-ecology, was considered a potentially important factor in the decision of whether to adopt the technologies, one village from each altitude category was selected for the survey. Each selected village had approximately 600 households, and 100 households were randomly selected from each, using a list of the names of the village's household heads. Of the total of 300 households, eight were not available for interviews. As five were randomly selected and added, the total number of households surveyed in the first round of our survey was 297.

Face-to-face questionnaire interviews were conducted with the self-identified household head in each selected household in three consecutive years, December 2009 to January 2010, January to February 2011, and February 2012. The survey components included the demographic characteristics of the household members, personal networks of the household head, and the knowledge and use of the agricultural technologies indicated in the previous section.

Geographic information system (GIS) coordinates were recorded for the positions of all surveyed households and major facilities. These data identify the households' distances from important locations and altitudes. The interviewers' movement paths during the survey were also recorded, and these paths were used to calculate the actual distances traveled between households and agricultural extension centers. Figure 1 depicts the geographic locations of all households surveyed and the extension centers. The black lines drawn between households denote the paths traveled by the 
interviewers. This map confirms that distances along the paths are far more accurate than the minimum straight-line distance between two given locations.

Although we conducted the household-level survey three times, the first survey did not focus on compost or row planting but on other agricultural technologies, such as conservation tillage. As a result, this paper primarily relies on the responses obtained from the second and third surveys. Some households refused to respond to certain questions regarding the social networks and agricultural technologies in the third survey, likely because we repeatedly asked the same detailed questions. As a result, our sample is based on the 208 households for which the necessary information is available for the two years. Although the number of households in the first survey was 297, and thus, the attrition rate is not low, we find no systematic difference in characteristics in the first year between households in and out of the sample.

\subsection{Social experiment}

One econometric issue for researchers attempting to estimate the effect of social networks on knowledge diffusion is that social networks are endogenously generated, as we will discuss in detail below. To alleviate this endogeneity problem in estimation, this study conducted a social experiment in which mobile phones were provided to randomly selected households to generate exogenous changes in the social networks in the region. In Ethiopia, the mobile phone penetration rate was only 8.3 subscriptions per 100 inhabitants in 2010, the year of our first survey, the third lowest in Africa (International Communications Union, 2013), and the penetration rate is even lower in rural areas. In our first survey in 2010, we found that 224 households of 297 (75\%) did not have mobile phones. Therefore, providing mobile phones on a large scale may have a sizable effect on social networks in the region.

Mobile phones were provided in the following manner. In May 2011, we called all of the surveyed self-identified household heads to meetings in each village, in which 272 of the 297 household heads participated. At the meeting, each household head was asked to draw a piece of paper from a box, and depending on the result, s/he was given a mobile phone with short message services (SMS), a mobile phone without SMS, or nothing, all with one-third probability. In practice, 98 did not 
receive a mobile phone, 87 won one without SMS, and 87 won one with SMS. In our sample of 208 households, the corresponding numbers are 75,72 , and 61 . We provided the household heads who were awarded mobile phones with instructions on how to use them, and for those who were awarded mobile phones with SMS, we also provided instructions on how to use SMS. In addition, we provided lists with the names and phone numbers of all mobile phone recipients in the area and the phone numbers of 27 local agricultural experts and five Ethiopian research assistants who already owned phones. We instructed the farmers that the mobile phones were the property of the research team and that they therefore should not give or sell them to others.

After providing the mobile phones, we organized a meeting in each village in each month from June to December 2011 to conduct a survey on mobile phone use and to determine whether each farmer still had a phone. In addition, we loaded the phones with credits worth approximately 30 minutes of domestic calls to ensure that the farmers could actually use the phones.

\subsection{Household characteristics}

There are three ethnic groups in the areas examined in this paper, Amhara, Oromo, and Gurage. In our sample, $40 \%$ are Amhara, 54\% are Oromo, and only 6\% are Gurage. The population can be divided into two religious groups, Christians (87\%) and Muslims (13\%). Most of the Christians are Orthodox Christians, whereas a few are Protestants.

The household characteristics are summarized in Table 1 . The average number of household members is 6.3 , and the household head is 45.5 years old on average. The average number of years of schooling completed by the household head and the most educated adult in the household is 4.7 and 8.7, respectively. The average area of farmland cultivated and owned by a household is 1.82 and 2.75 ha, respectively. The average distance from the nearest agricultural extension center is $6.6 \mathrm{~km}$ (4.1 miles).

We constructed a dummy variable for myopia from the following question asked in 2011: "Suppose that the government will give you either 1,000 birr one month from now or 2,000 birr one year from now. Which would you like to choose?” The dummy variable for myopia is one if the 
household head chose 1,000 birr one month from now and zero if s/he chose 2,000 birr one year from now. As shown in Table 1, 78\% of the households are myopic.

\subsection{Diffusion and adoption of agricultural technologies}

To examine the diffusion and adoption of agricultural technologies, the households were asked: (1) whether they understand how to implement each of the two technologies (compost and row planting); and (2) whether they used the technology in the last crop season, conditional on understanding it. Figure 2 indicates the situation from the sequence of adoptions for each technology in 2011 and 2012.

The left half of Figure 2 illustrates that the adoption of row planting increased dramatically during the two-year period. The number of users jumped from 15 (among 208) in 2011 to 110 in 2012, and the number of households that did not understand how to implement it declined from 158 to 29. In 2011, 36 households understood the technology but did not use it, while this was the case for 69 households in 2012, indicating that using a technology requires factors in addition to understanding it. In the case of compost depicted in the right half of Figure 2, we also observe that the number of households who know or use the technology increased substantially over the two years, whereas the change is less drastic than in the case of row planting.

\subsection{Social networks}

We collected data on the households' social networks in various ways. First, households were asked whether they know any extension agents in the village. The definition of "knowing" is that the respondent (the self-identified household head) could directly contact the person when needed, and conversely, the person could directly contact the respondent when needed. The definition of knowing was clearly stated to the respondent before the question was asked. If the respondent knew an extension agent, we also asked for the walking distance to the agent's home, how frequently the respondent met with the agent, and the agent's ethnicity and religion. If the respondent knew more than one agent, s/he was asked to choose the most familiar agent. In addition, we asked whether the 
household could borrow 500 birr from the agent and whether the household can discuss important personal matters with the agent. ${ }^{1}$ At the exchange rate when the survey was conducted, 500 birr was approximately equivalent to 30 US dollars and $17 \%$ of the median annual estimated income in our sample. These two questions indicate whether the tie between the household and extension agent is strong. Figure 3 shows that 186 households out of 208 (89\%) know an extension agent, whereas 57 (27\%) can borrow 500 birr from the agent and 111 (53\%) meet with an agent at least once every two weeks.

Second, to quantify the size of each household's personal social network of relatives and friends, we employ the "first-name-cue method" developed by McCarty et al. (1997), as explained below. We randomly selected 78 first names, 39 for men and 39 for women, from the list of names from the three villages. The respondent was asked whether s/he knows someone with the first name at the top of the list of 78 names. We employ the same definition of knowing as before and informed the respondent of the definition before asking the question. If the respondent knows a person with this first name, we asked about the nature of their relationship with the person, the walking time (in minutes) to the person's house, how frequently the respondent meets with the person, and his/her ethnicity and religion. We also asked whether the household could borrow 500 birr from the person and whether they can discuss important personal matters with the person. We repeated this process from the top of the list of names to the bottom, until the total number of first names for which the respondent knows any person reaches 14 . These 14 names represent a subset of the respondent's personal social network. We asked these questions in each of the three surveys using the same name list.

From this information, we constructed an index of the size of personal social network of each household defined as the number of first names for which the respondent knows specific persons among the first 14 names on the list. Figure 4(1) illustrates the distribution of this measure of personal network size in 2012. Three households only know three individuals with names among the first 14, whereas one knows individuals for each of the 14 names. The average number of individuals the

\footnotetext{
${ }^{1}$ The two questions are: "Do you know this person well enough that you could borrow 500 birr from him/her?" and "Do you know this person well enough that you could discuss important personal matters with him/her?"
} 
respondent knows with names on the list was 8.79, and the distribution of this measure for the number of network ties appears to have the standard bell shape. Figure 4(2) illustrates the distribution of the number of individuals with names among the first 14 on the list that the household knows and can borrow 500 birr from. This parameter is an index of the size of personal networks with reliable partners, measuring the level of a type of strong ties. Its distribution is left-skewed compared to the distribution of the number of ties based on simply knowing an individual presented in Figure 4(1). This left-skewed distribution indicates that although households know many people, it is often difficult to create strong ties. In addition, Figure 4(3) illustrates the distribution of personal network size based on frequent meetings, proxied by the number of individuals with names among the first 14 on the list that the household knows and meets with at least once every two weeks. Its mean is 5.97, smaller than the mean for the number of ties based on knowing (8.79) but larger than the mean for the number of strong ties with reliable partners (3.47). Below, we will see how each of these different types of network measure affects the diffusion of technological information and practice.

Finally, to quantify the level of clustering in the personal social networks, we randomly select 14 pairs from all possible pairs of the 14 names held by individuals who each household knows ${ }^{2}$ and asked the respondent whether the two paired persons know one another. For example, if the respondent knows individuals named "Tesfaye” and "Medina," we asked the respondent whether Tesfaye and Medina know one another. Then, the number of pairs of individuals who know one another out of the 14 pairs indicates the level of clustering in the household's personal network. In other words, if many of a respondent's friends know one another, the respondent's social network is considered highly clustered. Figure 5 presents the distribution of the index of personal network clustering. The index takes a value of 14, the maximum, for more than 50 households, or approximately $25 \%$. This result suggests that networks in this region are highly clustered, likely because most of the households' acquaintances live close to one another. In fact, $91.6 \%$ of all acquaintances specified by the households in our survey live within a 60-minutes walking distance.

\footnotetext{
${ }^{2}$ The total number of possible pairs is $14 \times 13 / 2=91$.
} 


\section{Empirical Methodologies}

\subsection{Estimation equations}

When we estimate how social networks affect the diffusion of information regarding and use of new agricultural knowledge, we are concerned about possible differences between the two types of diffusion. Therefore, we estimate the following two linear probability models, one for knowing how to implement a technology, or understanding it, and the other for using a technology conditional on understanding it:

$$
\begin{gathered}
\operatorname{KNOW}_{i, 2012}^{j}=\alpha^{K}+\beta^{K} N E T_{i, 2012}^{\prime}+\delta^{K} x_{i, 2011}^{\prime}+\varepsilon_{i, 2012}^{K} \text { for } \mathrm{KNOW}_{i, 2011}^{j}=0, \\
U S E_{i, 2012}^{j}=\alpha^{U}+\beta^{U} N E T_{i, 2012}^{\prime}+\delta^{U} x_{i, 2011}^{\prime}+\varepsilon_{i, 2012}^{U} \text { for } U S E_{i, 2011}^{j}=0 \text { and } K N O W_{i, 2012}^{j}=1,
\end{gathered}
$$

where $K N O W_{i t}^{j}=1$ if household $i$ knows how to implement technology $j$ ( $j$ = row planting, compost) in year $t$ and zero otherwise; $U S E_{i t}^{j}=1$ if household $i$ uses technology $j$ in year $t$ and zero otherwise; $N E T_{i, 2012}$ is a vector of social network variables in 2012 explained in detail below. The vector $X_{i, 2011}$ includes other potential determinants of the diffusion and adoption of technology $j$ in year 2011, such as years of schooling of the household head, the log of cultivated farmland area, the dummy variable for myopia, the distance from the nearest extension center, and dummies for ethnicities, religions, and villages. We estimate equation (1) for households that did not know how to implement the technology in 2011, as the independent variables in 2011 and 2012 included in equation (1) cannot cause the household to understand the technology if the household came to understand the technology in or before 2010. Similarly, we estimate equation (2) for households that did not use the technology in 2011 but knew how to use it in 2012. In this manner, we can examine how the use of a new technology is determined, conditional on knowing how to use it, or conversely, why some households who know how to use the technology do not actually use it.

An obvious disadvantage of this method is that the results are generated from a non-random sample. Households that did not understand row planting or composting in the 2011 survey tend to be less educated, cultivate less farmland, and have smaller social networks than those who already understood it. Therefore, our results may not be generalizable to the entire population. 


\subsection{Hypotheses on the effects of social networks}

Social networks may affect the diffusion of information and practice, but the effect can vary depending on the structure of the networks. First, in addition to the effect of the size of personal networks, we are interested in the effect of clustered networks in which individuals are densely connected with one another. Centola (2010) finds that clustering is more important for the adoption of new behaviors, as it requires reinforcement from multiple neighbors in the network. Similarly, farmers who receive the same information about a new agricultural technology from many others are more likely to understand the technology well and use it than those who only receive information from one person.

Therefore, we examine whether the effects of the size of the personal social network of each household on the diffusion of information and practice vary depending on the level of network clustering. As we explained in Section 3.5, the size of each household's personal network is measured by the number of first names for which the household head knows specific persons among the first 14 names on the list. The level of clustering in personal networks is measured by the number of pairs of the household's acquaintances who know one another among the 14 randomly selected pairs of acquaintances. Then, we first estimate the effect of the number of individuals known by the household head with names on the list on understanding and using row planting and composting to determine whether the size of each household's personal network matters. Furthermore, we estimate the effect of the interaction term between the personal network size and personal network clustering indices to determine how the total effect of the number of ties changes depending on the density. That is, the right side of the estimation equations includes $\beta_{1}$ (index of personal network size) $+\beta_{2}$ (index of personal network size $\times$ index of personal network clustering), and thus, the total effect of the number of ties is $\beta_{1}+\beta_{2} \times$ (index of personal network clustering). A positive $\beta_{2}$ implies that clustering enhances the effect of social networks, supporting the finding of Centola (2010).

Second, we examine the effect of external ties, or bridging ties, with other societies. As observed by Tiwana (2008) and Rost (2011), external ties could promote knowledge diffusion and innovation. Our study is particularly interested in ties with agricultural extension agents, as farmers can access 
new agricultural technologies most quickly through these ties. Thus, we estimate the effect of a dummy variable for knowing any extension agent in equations (1) and (2).

Furthermore, we investigate whether the strength of network ties influences the effect of networks. Strong ties with individuals on whom the household can rely may have a different effect than weak ties. Therefore, we measure the size of strong ties using the number of individuals with names among the first 14 on the list whom the household knows and from whom they can borrow 500 birr. Moreover, we use a dummy variable for knowing any extension agent and being able to borrow 500 birr from him/her to indicate a strong tie with the extension agent.

The strength of ties may also be related to the frequency of meetings. When farmers meet others more often, they may receive more information from face-to-face communication. Thus, we measure the size of personal networks based on frequent meetings using the number of individuals with names among the first 14 on the list whom the household knows and meets with at least once every two weeks, and external ties based on frequent meetings are measured by whether the household knows and meets with an extension agent at least once every two weeks.

\subsection{Endogeneity of the social network variables}

Estimates of the effect of social networks on knowledge diffusion may be biased due to the endogeneity of the social network variables. Correlation between knowledge diffusion and social networks may be observed when social networks do not lead to knowledge diffusion but if members of social networks share similar unobservable characteristics that are potential determinants of knowledge diffusion (Manski, 1993). To alleviate potential biases due to endogeneity, some existing studies use social experiments in which social networks are exogenously created (Centola, 2010) or information is provided to exogenously determined individuals (Duflo et al., 2004). We also conducted a social experiment in which we provided mobile phones with and without SMS to randomly selected households to generate exogenous changes in social networks.

Accordingly, when we estimate the effect of social networks on knowledge diffusion, we use a dummy variable for households that received any type of mobile phone (hereafter, the mobile phone dummy) and another dummy for the receipt of a mobile phone with SMS (the SMS dummy) as 
instruments. To determine the validity of the instruments, we first estimate the effect of the receipt of mobile phones on a variety of network variables by ordinary least squares (OLS) estimations. We control for other exogenous variables, such as the lagged dependent variable, the distance from the nearest farmer training center, the myopia dummy, and dummy variables for villages, ethnicity, and religion. Table 2 only presents the coefficients for the mobile and SMS dummies for brevity. The results indicate that having a mobile phone with SMS has a positive and significant effect on the personal network size index, i.e., the number of instances in which the household knows at least one individual with a name among the first 14 (column [1]), whereas having a mobile phone has a positive and significant effect on knowing an extension agent that the household trusts (column [5]). Further, we estimate the direct effect of the provision of mobile phones on the diffusion and adoption of agricultural knowledge. Columns (8)-(11) of Table 2 indicate that having a mobile phone with or without SMS has no significant impact on knowing or using either of the two technologies examined in this study. To summarize, the provision of mobile phones led to the expansion of certain types of social networks, although it did not directly affect the diffusion of information or practice of either technology. Therefore, the mobile phone dummy and the SMS dummy are valid instruments for the social network variables.

In addition, we also use lagged endogenous regressors, as are often used in existing studies, such as Blundell and Bond (1998), and the lagged number of household members, which can affect the size of household personal networks, as instruments. Lagged regressors can be valid instruments, as they are correlated with the independent variables but uncorrelated with the error term. Then, we perform the generalized method of moments (GMM) estimation on the linear probability models in equations (1) and (2). To determine whether instruments are exogenous, we implement the overidentification test developed by Hansen (1982).

Another possible econometric model is an instrumental-variable probit model, where equation (1) or (2) is jointly estimated with linear equations for each of the social network variables on the instruments. Using the two-step approach developed by Newey (1987), the results from the instrumental-variable probit model are similar to those obtained from the linear probability model using GMM. Because the magnitude of the coefficients is easier to interpret in linear probability 
models than in probit models, we will focus on results from the GMM estimations.

\section{Results}

\subsection{Estimation results}

Tables 3 and 4 present the results from the estimation of knowing how to implement (equation [1]) and using (equation [2]) row planting, respectively, whereas Tables 5 and 6 present the results for understanding and using composting. In all GMM estimations, the $p$ value of Hansen's $J$ statistic presented in the bottom row indicates that the instruments are orthogonal to the error term. Moreover, when we regress each endogenous variable on the instruments and exogenous variables using OLS, in all cases, we reject the null hypothesis that all of the coefficients on the instruments are zeros. Therefore, the instruments are valid for the GMM estimations. In the following, we will summarize the results and then discuss their implications.

Column 1 in Table 3 indicates that the size of personal social networks does not have any significant effect on the diffusion of information on row planting. Column 2 indicates that the effect of the interaction term between the indices of the size and clustering of personal networks is also insignificant, indicating that social networks do not affect information diffusion, even when the networks are clustered. Regarding columns 3-6, we find no effect of social networks with relatives and friends, even when we focus on strong ties based on subjective reliance or frequent meetings.

By contrast, columns 1-4 in Table 3 indicate that the effect of knowing an extension agent and the effect of knowing any reliable agent, i.e., knowing and being able to borrow 500 birr from any agent, is positive and statistically significant at the $10 \%$ level. The magnitude of the coefficient implies that when knowing an extension agent, the probability of understanding row planting increases substantially, by more than $100 \%{ }^{3}$ The effect of knowing any reliable agent is smaller than the effect of simply knowing any agent, and the effect of knowing and frequently meeting any agent is

\footnotetext{
${ }^{3}$ Using the instrumental-variable probit model explained in Section 4.3, the marginal effect of knowing an agent at the mean is 0.466 .
} 
insignificant (columns 5 and 6). Years of schooling of the household head have a positive and significant effect in columns 5 and 6, although the effect is not robust. The size of the farmland cultivated by the household has no significant effect.

Table 4 indicates that once households know how to implement row planting, they are more likely to use it when their farmland is larger. The effects of education level and myopia are positive but not always significant. The network variables have no significant effect.

The results for understanding composting, presented in Table 5, are quite different from those for understanding row planting in the following two respects. First, whereas the size of personal networks alone has no significant effect, as in the case of row planting, the interaction term between the size and level of clustering of personal networks has a positive and significant effect for composting. To quantify the effect, let us assume, based on the summary statistics in Figures 4 and 5, that a hypothetical household has an average-sized personal network (8.79) and the average clustering level (11.07). Suppose that this household increases the level of network clustering by one standard deviation (2.63). Then, from the results in column 2 of Table 5, we conclude that the probability of understanding composting increases by $21.9 \%(=0.00947 * 8.79 * 2.63)$. Thus, the effect of network clustering is large. Columns 4 and 6 illustrate that the effect of the interaction term is positive and significant when we focus on networks with reliable partners or based on frequent meetings. The magnitude of the effect using the sample averages is similar to that from column (1). Second, knowing an extension agent has an insignificant effect for composting, unlike in the case of row planting. By contrast, knowing a reliable extension agent has a positive, statistically significant, and economically large effect.

Finally, the results for using compost conditional on understanding it, presented in Table 6, indicate that the only significant effect comes from the distance from the nearest farmer training center; however, the effect is not robust to various specifications.

\subsection{Discussion}

The findings above clearly demonstrate that the effect of social networks on the diffusion and adoption of new technologies varies substantially depending on the characteristics of the networks and 
technologies. In the case of row planting, simply knowing an extension agent who is connected to the ultimate source of new agricultural technologies in Ethiopia, the EIAR, has a substantial impact on understanding the technology. This finding is consistent with that of Watts and Strogatz (1998) that networks with ties across network clusters result in the more rapid spread of infectious diseases. The similarity is likely because row planting is a simple technology and can be easily understood by farmers, just as infectious diseases can be easily transmitted.

In contrast, making and using compost is more difficult and requires several procedures, as explained in Section 2.2. When compost is made and used inappropriately, it may lead to few positive or even negative effects. Likely as a result of this technical complexity, simply knowing an extension agent or many villagers does not help farmers understand how to implement composting. However, the clustering of social networks promotes understanding how to implement composting, as people in clustered networks have more opportunities to receive the same information from many friends in the cluster and are thus more likely to understand the complicated process of making compost. According to our 2012 survey, among the 208 households in the sample, 205, or nearly all, have heard about composting, but only 173 knew how to implement it. In other words, 32 (= 205 - 173) households did not know how to implement composting, although they were aware of it. This evidence clearly demonstrates the difference between being aware of a technology and understanding it. Hearing the same information from multiple sources in the network repeatedly may help farmers understand the technology. This finding is similar to that of Centola (2010), as both emphasize the importance of information flows from multiple sources for the diffusion and adoption of new knowledge. One notable difference between our results and those of Centola is that we find that reinforcement from multiple sources is necessary for understanding, rather than adopting, as found in Centola (2010).

To examine whether clustered networks promote flows of the same information from multiple sources, we perform the following test. Our survey asked each household head about the number of persons from whom the household received the same information as from the most influential information source. Thus, we employ GMM to estimate the effect of the interaction term between the size and clustering level of personal networks on the number of information sources using the dummies for mobile phones and SMS, lagged regressors, and the lagged number of household 
members as instruments. We find an insignificant effect of the interaction term for row planting (column 1 of Table 7), whereas its effect is positive and significant for compost (column 2). These findings confirm our assumption that clustered networks promote the flow of the same knowledge from multiple sources, particularly when the knowledge is complex.

Networks with extension agents are also helpful in understanding composting when the relationship is associated with reliance, although meeting an extension agent frequently is not. These contrasting results imply that because information from a reliable extension agent can be trustworthy, it is more likely to be absorbed and implemented by farmers. By meeting an extension agent frequently, farmers may have more opportunities to receive information about composting through face-to-face communications, but unless the agent is reliable, the farmers cannot understand the information provided by the agent.

Using row planting or compost is not affected by many factors, conditional on knowing the technology. Farmers are more likely to use row planting when their cultivated farmland is larger. As row planting does not require any specific equipment or initial investment, the positive effect of farmland area, which is related to the income level, is somewhat surprising. This evidence may suggest that farmers with large parcels of farmland can experiment with row planting on part of their farmland. Moreover, farmers are more likely to use compost when the distance from the nearest farmer training center is longer. As the distance from the nearest training center is closely related to the distance from markets, this evidence suggests that farmers are more willing to use compost when they live far from markets where chemical fertilizer is available. In any case, our results indicate that social networks are more important in understanding technologies, whereas other household characteristics play a more important role in using them.

\section{Summary and Conclusions}

This paper investigates effects of social network structure on the diffusion and adoption of agricultural technologies using household-level panel data from Ethiopia. We contribute to the literature by focusing on the role of external ties and clustered personal networks. Another contribution is to correct for possible biases due to the endogeneity of social networks using a social 
experiment in which we provide mobile phones to randomly selected households. Our findings suggest that the effect of social networks varies depending on the structure of networks and characteristics of technologies. Understanding a simple technology is primarily determined by whether farmers know an agricultural extension agent, indicating the importance of external ties with agricultural researchers. However, understanding a more complicated technology is not promoted by knowing an extension agent but by knowing a reliable agent and having clustered networks with relatives and friends. This finding suggests that knowing and understanding more complicated technologies require strong ties and flows of the same information from multiple sources. 
Figure 1. Geography of the Surveyed Households

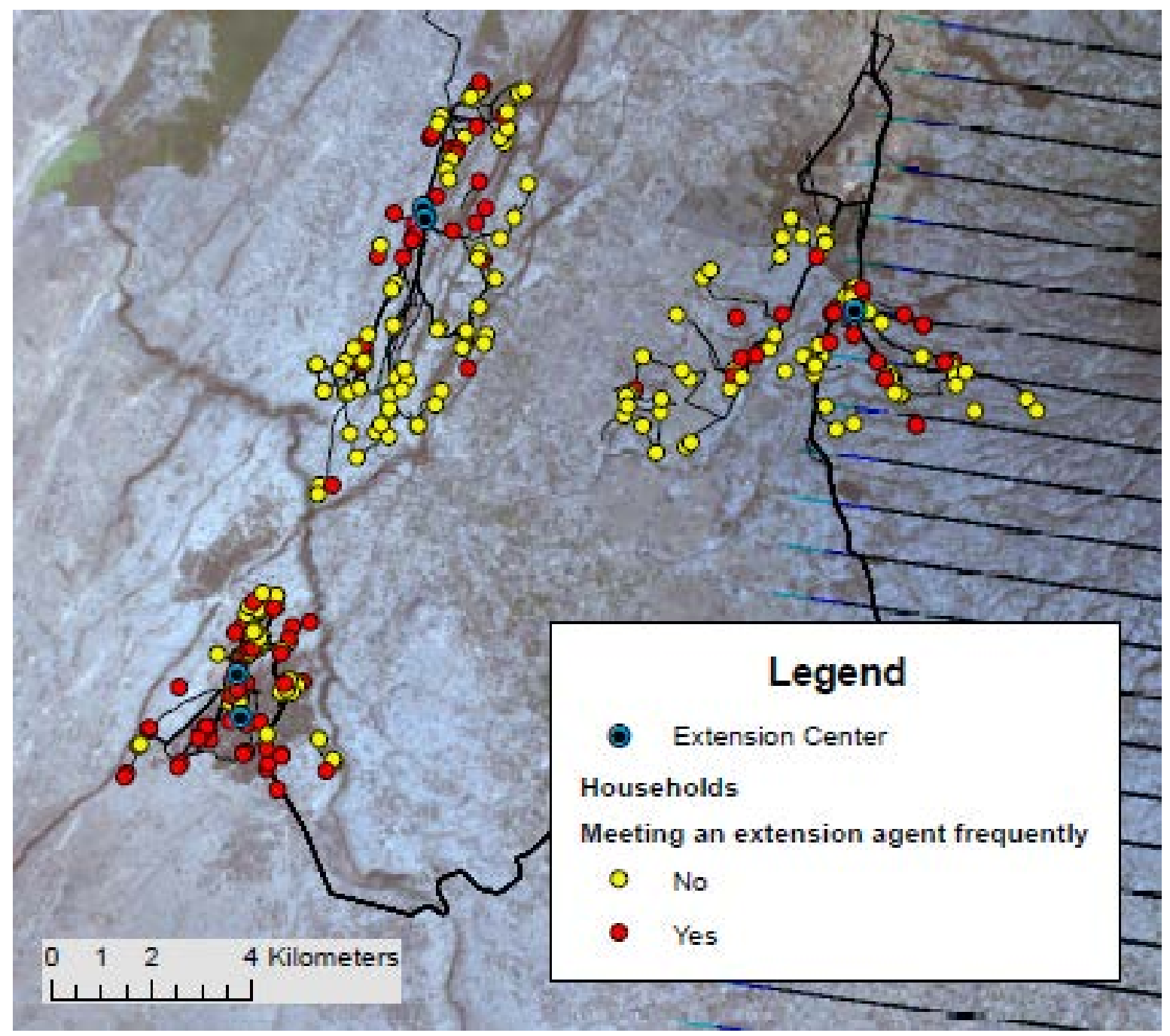


Figure 2. Diffusion and Adoption of Two Agricultural Technologies

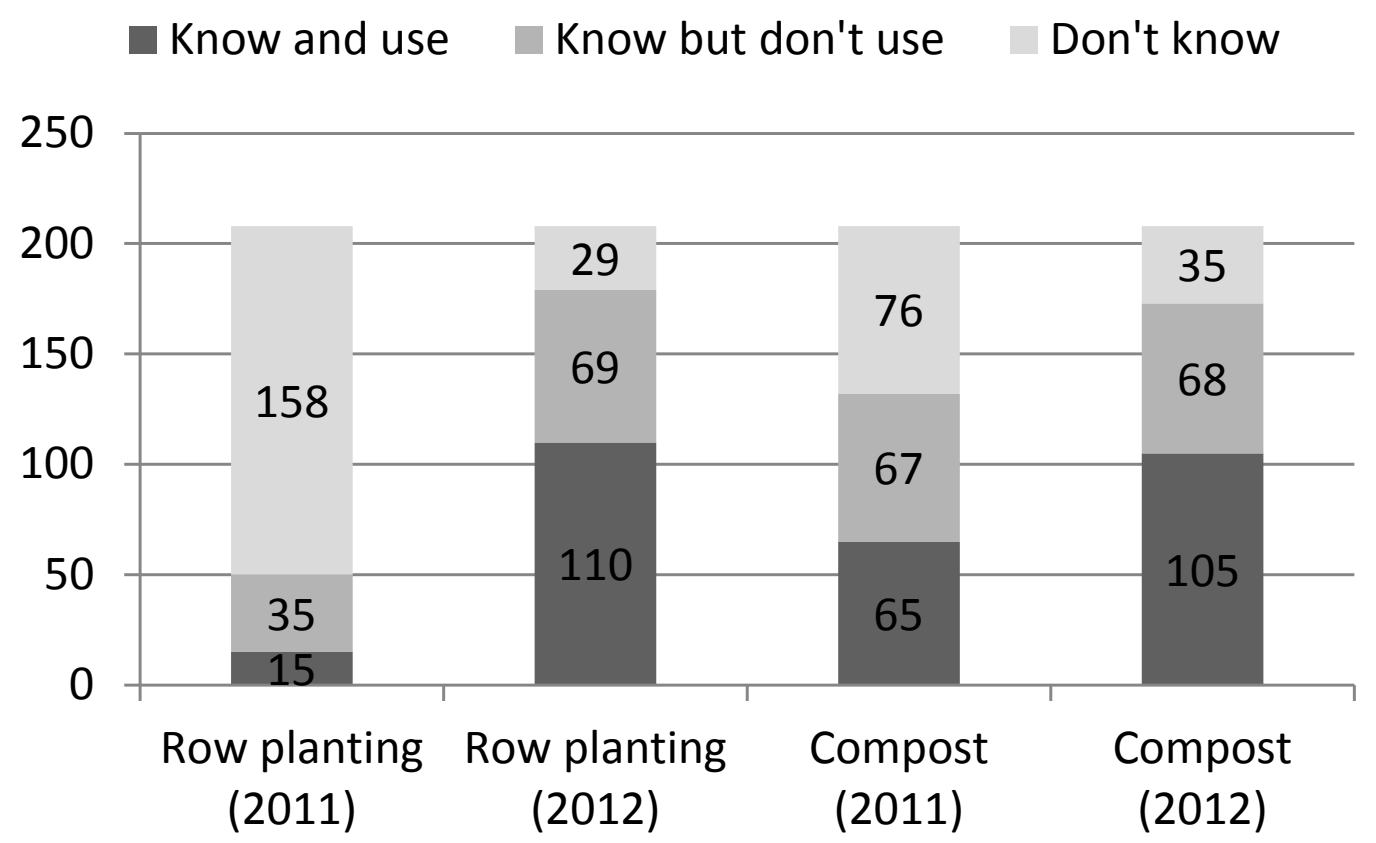

Notes: The numbers in the bars denotes the number of respondents in each category. The total number of respondents for row planting is 222, whereas the corresponding figure for compost is 223. 
Figure 3. Networks with Extension Agents (2012)

Yes No

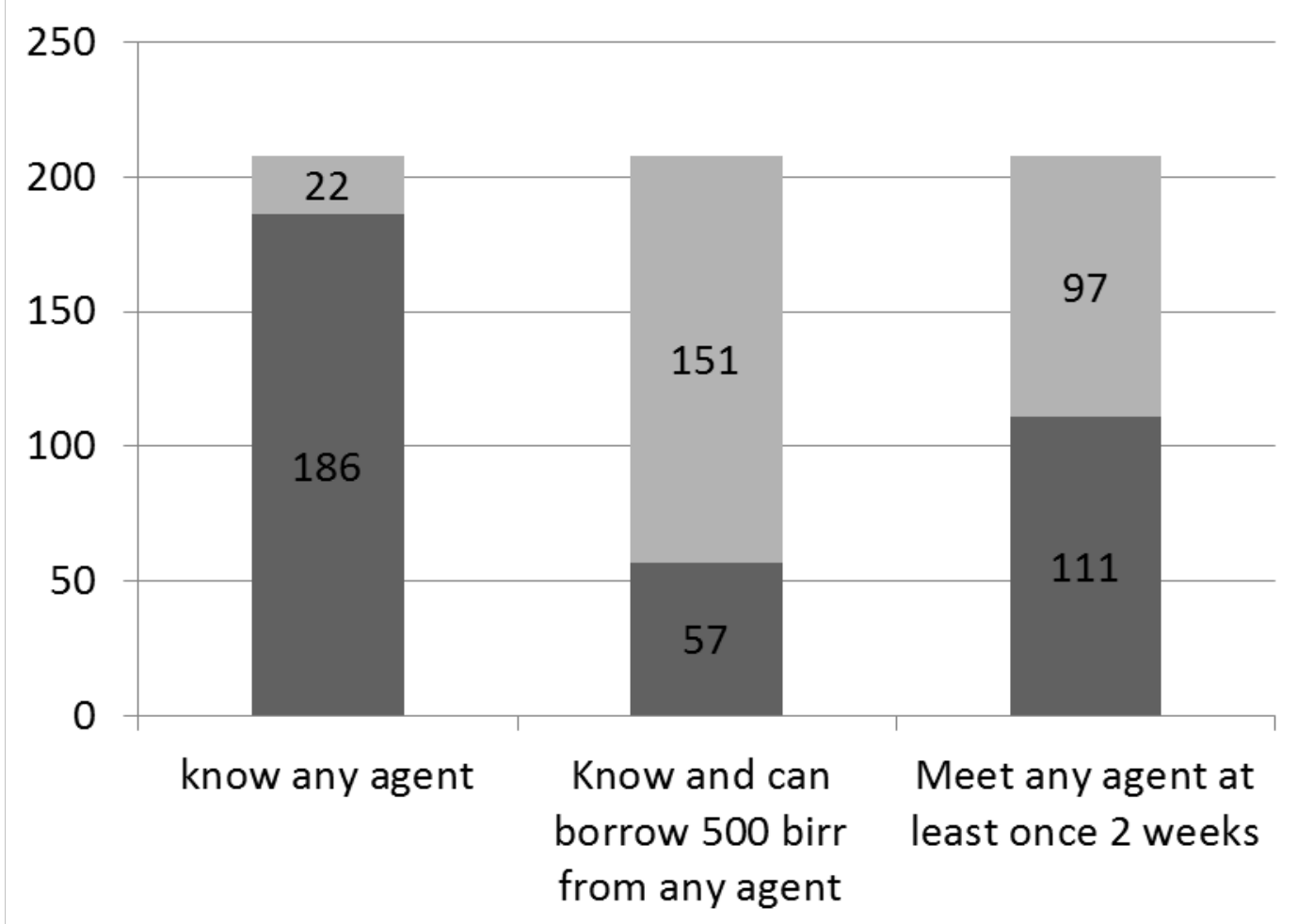


Figure 4. Indices of the Size of Personal Social Networks of Households

(1) Size of personal networks based on knowing:

Distribution of the number of instances in which the household knows one or more individuals with names among the first 14 on the list

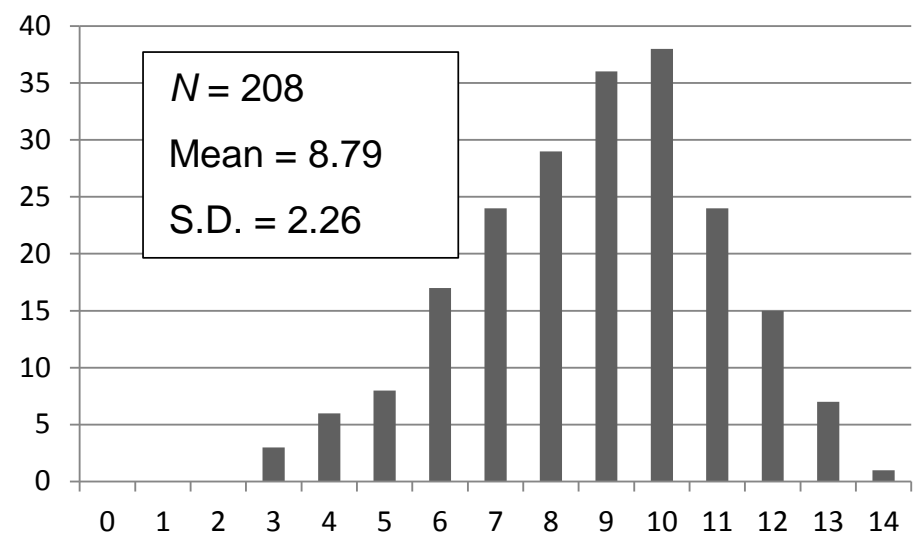

(2) Size of personal networks with reliable partners:

Distribution of the number of instances in which the household knows one or more individuals with names that appear among the first 14 on the list and from whom the household could borrow 500 birr (30 US dollars)

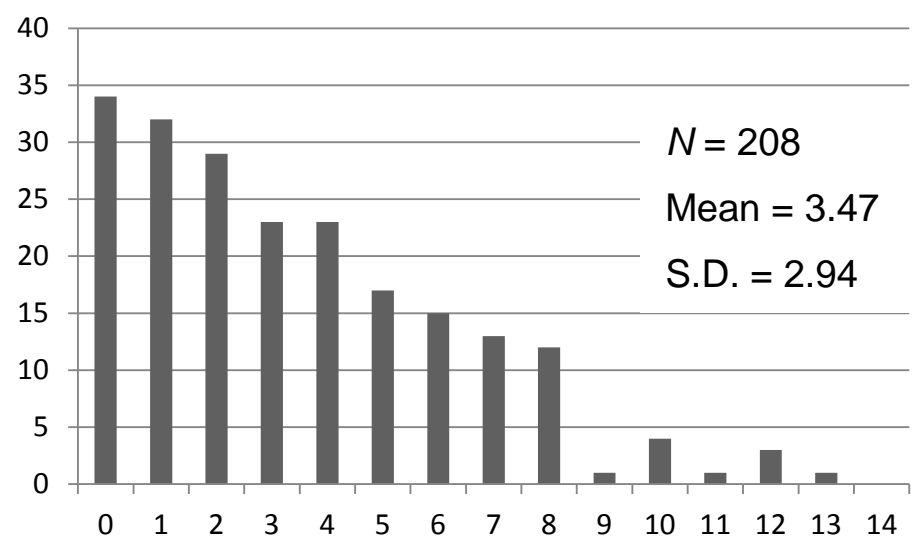

(3) Size of personal networks based on frequent meetings:

Distribution of the number of instances where the household knows one or more individuals with names among the first 14 on the list that the household knows and meets with at least once every two weeks

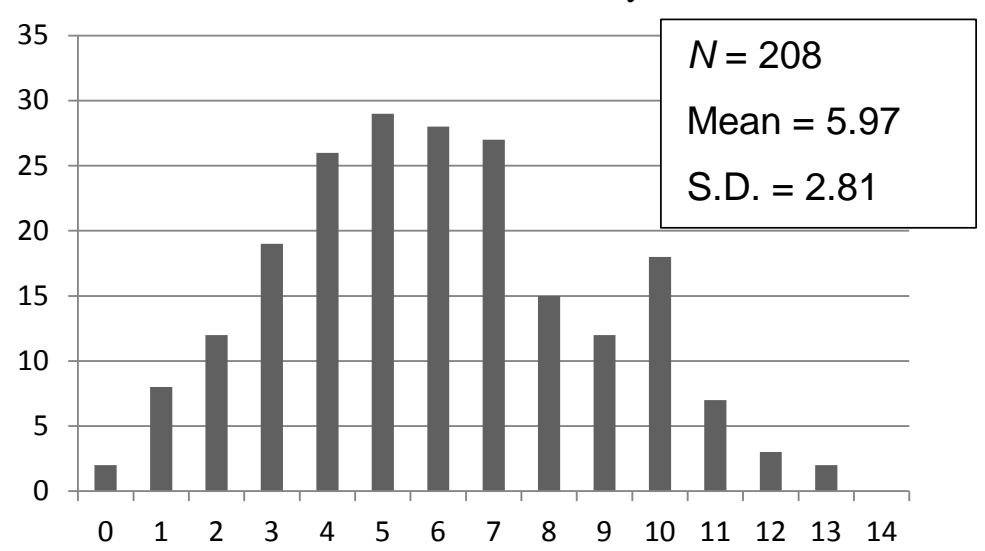


Figure 5. Index of Clustering of Personal Social Networks

Distribution of the number of pairs of individuals known by the household who have names that appear on the list and know one another

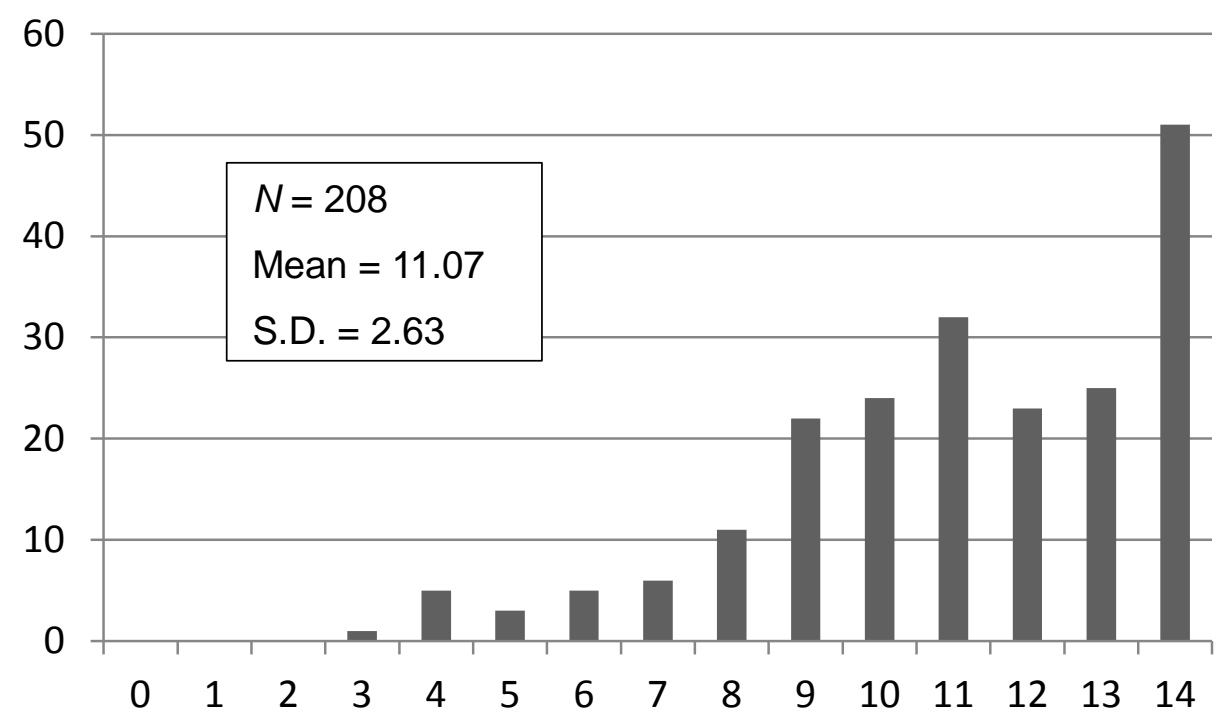

Note: There are a total of 208 households. 
Table 1: Summary Statistics

\begin{tabular}{|c|c|c|c|c|}
\hline$N=208$ & Mean & $\begin{array}{l}\text { Standard } \\
\text { deviation }\end{array}$ & Minimum & Maximum \\
\hline Number of household members & 6.31 & 2.80 & 1 & 25 \\
\hline Age of household head & 45.51 & 14.48 & 22 & 84 \\
\hline Years of schooling of household head & 4.68 & 3.80 & 0 & 12 \\
\hline Years of schooling of the most educated household member & 8.70 & 2.86 & 0 & 16 \\
\hline Cultivated farmland (hectare) & 1.82 & 1.16 & 0.25 & 8.00 \\
\hline Log of cultivated farmland & 0.41 & 0.63 & -1.39 & 2.08 \\
\hline Owned farmland (hectare) & 2.75 & 10.37 & 0 & 150 \\
\hline Myopia dummy (one if myopic) & 0.78 & 0.41 & 0 & 1 \\
\hline Distance from the nearest agricultural extension center $(\mathrm{km})$ & 6.59 & 6.40 & 0.11 & 22.47 \\
\hline
\end{tabular}


Table 2: Effects of Randomly Distributing Mobile Phones

\begin{tabular}{|c|c|c|c|c|c|c|c|}
\hline & (1) & $(2)$ & (3) & $(4)$ & (5) & (6) & (7) \\
\hline & $\begin{array}{l}\text { Index of the } \\
\text { size of } \\
\text { personal } \\
\text { networks }\end{array}$ & $\begin{array}{l}\text { Index of } \\
\text { personal } \\
\text { network } \\
\text { clustering }\end{array}$ & $\begin{array}{l}\text { Index of the } \\
\text { size of } \\
\text { personal } \\
\text { networks } \\
\text { with } \\
\text { reliable } \\
\text { partners }\end{array}$ & $\begin{array}{l}\text { Index of the } \\
\text { size of } \\
\text { personal } \\
\text { networks } \\
\text { based on } \\
\text { frequent } \\
\text { meetings }\end{array}$ & $\begin{array}{l}\text { Knowing } \\
\text { an } \\
\text { extension } \\
\text { agent }\end{array}$ & $\begin{array}{l}\text { Knowing } \\
\text { and can } \\
\text { borrow } 500 \\
\text { birr from an } \\
\text { extension } \\
\text { agent }\end{array}$ & $\begin{array}{l}\text { Knowing } \\
\text { and } \\
\text { frequently } \\
\text { meeting an } \\
\text { extension } \\
\text { agent }\end{array}$ \\
\hline \multirow[t]{2}{*}{ Mobile phone } & -0.0171 & -0.292 & 0.168 & 0.0491 & 0.0158 & $0.127 *$ & 0.0122 \\
\hline & $(0.314)$ & $(0.310)$ & $(0.435)$ & (0.393) & $(0.0517)$ & $(0.0653)$ & $(0.0772)$ \\
\hline \multirow[t]{2}{*}{ SMS } & $0.644^{*}$ & 0.00293 & -0.594 & 0.0455 & 0.0238 & 0.0391 & -0.0326 \\
\hline & $(0.341)$ & $(0.339)$ & $(0.470)$ & $(0.423)$ & $(0.0557)$ & $(0.0709)$ & $(0.0837)$ \\
\hline Observations & 208 & 208 & 208 & 208 & 207 & 208 & 208 \\
\hline \multirow[t]{3}{*}{ R-squared } & 0.331 & 0.517 & 0.241 & 0.326 & 0.044 & 0.261 & 0.173 \\
\hline & (8) & (9) & (10) & $(11)$ & & & \\
\hline & $\begin{array}{l}\text { Knowing } \\
\text { row } \\
\text { planting }\end{array}$ & $\begin{array}{l}\text { Using row } \\
\text { planting }\end{array}$ & $\begin{array}{l}\text { Knowing } \\
\text { compost }\end{array}$ & $\begin{array}{c}\text { Using } \\
\text { compost }\end{array}$ & & & \\
\hline \multirow[t]{2}{*}{ Mobile phone } & 0.0846 & 0.0559 & -0.0492 & 0.00569 & & & \\
\hline & $(0.0725)$ & $(0.0916)$ & $(0.133)$ & $(0.116)$ & & & \\
\hline \multirow[t]{2}{*}{ SMS } & 0.00447 & -0.0427 & 0.181 & -0.132 & & & \\
\hline & $(0.0794)$ & $(0.0977)$ & $(0.139)$ & $(0.125)$ & & & \\
\hline Observations & 158 & 165 & 76 & 111 & & & \\
\hline R-squared & 0.032 & 0.084 & 0.120 & 0.096 & & & \\
\hline
\end{tabular}

Notes: The results are based on OLS estimation. Standard errors are in parentheses. ***, **, and * signify statistical significance at the 1, 5, and 10\% levels, respectively. The lagged dependent variable, the distance from the nearest farmer training center, the myopia dummy, and the dummies for ethnicity, religion, and villages are included but not reported for brevity. The index of the personal network size is the number of instances where the household knows at least one individual whose name appears among the first 14 on the list, and the index of the personal network clustering is the number of pairs who know one another among the 14 randomly selected pairs of household acquaintances. 
Table 3: Determinants of the Diffusion of Row Planting

(1)

Dependent variable
(2)

(3)

Knowing row planting in 2012

conditional on not knowing it in 2011
Personal network size

--- × personal network clustering

Personal network size with reliable partners

--- $\times$ personal network clustering

Personal network size based on frequent meetings

--- × personal network clustering

Knowing any extension agent

1.289*

(0.779)

Knowing any reliable agent

Knowing \& meeting any agent

Years of schooling

Log of cultivated land

Myopia

Distance from farmer training center

Observations

$P$ value of Hansen $J$ statistic

$\begin{array}{cc}-0.0281 & -0.0249 \\ (0.0311) & (0.0334) \\ & -0.000431 \\ & (0.00246)\end{array}$

$0.00981 \quad-0.0564$

$(0.0253) \quad(0.0585)$

0.00613

(0.00467)
0.587* $0.610 *$

(0.305) (0.316)

$-0.434 \quad-0.389$

(0.550) (0.524)

$\begin{array}{cccccc}-0.00287 & -0.00252 & 0.00392 & 0.00438 & 0.0168 * & 0.0169 * \\ (0.0154) & (0.0149) & (0.00979) & (0.00980) & (0.00971) & (0.00949)\end{array}$

$\begin{array}{llllll}0.0191 & 0.0198 & -0.0117 & -0.0126 & -0.0226 & -0.0222\end{array}$

$\begin{array}{llllll}(0.0574) & (0.0572) & (0.0542) & (0.0546) & (0.0688) & (0.0671)\end{array}$

$\begin{array}{llllll}0.0586 & 0.0634 & 0.0176 & -0.0271 & -0.140 & -0.107\end{array}$

$\begin{array}{llllll}(0.104) & (0.119) & (0.0728) & (0.0828) & (0.113) & (0.117)\end{array}$

$\begin{array}{llllll}0.0237 & 0.0240 & 0.0150 & 0.0150 & -0.0119 & -0.00544\end{array}$

$\begin{array}{cccccc}(0.0227) & (0.0224) & (0.0175) & (0.0176) & (0.0363) & (0.0355) \\ 158 & 158 & 158 & 158 & 158 & 158\end{array}$

$0.931 \quad 0.927$

0.615

0.797

0.573

0.592

Notes: The results are based on GMM estimations using a linear probability model. Standard errors are in parentheses. ***, $* *$, and * signify statistical significance at the 1, 5, and 10\% levels, respectively. Dummies for ethnicity, religion, and villages are included but not reported for brevity. The personal network size indicates the number of is the number of instances where the household knows at least one individual whose name appears among the first 14 on the list, whereas the personal network clustering represents the number of pairs who know one another among the 14 randomly selected pairs of household acquaintances. 
Table 4: Determinants of Adoption of Row Planting

\section{(1)}

(2)

(3)

(4)

(5)

(6)

Dependent variable

Using row planting in 2012

conditional on not using it in 2011 and knowing it in 2012

Personal network size

--- $\times$ personal network clustering

Personal network size with reliable partners

--- × personal network clustering

Personal network size based on frequent meetings

--- × personal network clustering
$-0.0449 \quad-0.0378$

(0.0328) (0.0363)

$-0.00118$

(0.00298)

$\begin{array}{cc}-0.0143 & 0.0272 \\ (0.0356) & (0.0664) \\ & -0.00368 \\ & (0.00548)\end{array}$

$-0.0289 \quad-0.0389$

(0.0251) (0.0448)

0.00101

(0.00337)
Knowing any extension agent

$-1.193$

$-1.068$

(1.448)

(1.351)

Knowing any reliable agent

Knowing \& meeting any agent

Years of schooling

Log of cultivated land

Myopia

Distance from farmer training center

Observations

$P$ value of Hansen $J$ statistic

\begin{tabular}{cccccc} 
& & 0.0848 & 0.0976 & & \\
& & $(0.355)$ & $(0.354)$ & & \\
& & & & 0.0316 & 0.0253 \\
0.0280 & 0.0262 & $0.0178^{*}$ & $0.0175^{*}$ & 0.0165 & 0.0164 \\
$(0.0186)$ & $(0.0174)$ & $(0.0104)$ & $(0.0104)$ & $(0.0101)$ & $(0.0100)$ \\
$0.243^{* * *}$ & $0.244^{* * *}$ & $0.203^{* * *}$ & $0.207 * * *$ & $0.213^{* * *}$ & $0.211^{* * *}$ \\
$(0.0719)$ & $(0.0730)$ & $(0.0620)$ & $(0.0636)$ & $(0.0570)$ & $(0.0570)$ \\
0.153 & 0.170 & $0.149 *$ & $0.178^{*}$ & $0.163 *$ & 0.153 \\
$(0.111)$ & $(0.121)$ & $(0.0897)$ & $(0.101)$ & $(0.0924)$ & $(0.102)$ \\
-0.0336 & -0.0316 & -0.00920 & -0.00729 & -0.0205 & -0.0223 \\
$(0.0286)$ & $(0.0269)$ & $(0.0256)$ & $(0.0255)$ & $(0.0347)$ & $(0.0366)$ \\
\hline 164 & 164 & 165 & 165 & 165 & 165 \\
0.935 & 0.916 & 0.857 & 0.836 & 0.873 & 0.868 \\
\hline
\end{tabular}

Notes: The results are based on GMM estimations using a linear probability model. Standard errors are in parentheses. $* * *$, $* *$, and * signify statistical significance at the 1, 5, and 10\% levels, respectively. Dummies for ethnicity, religion, and villages are included but not reported for brevity. The personal network size indicates is the number of instances where the household knows at least one individual whose name appears among the first 14 on the list, whereas the personal network clustering represents the number of pairs who know one another among the 14 randomly selected pairs of household acquaintances. 
Table 5: Determinants of the Diffusion of Compost

\section{(1)}

(3)

Knowing compost in 2012

conditional on not knowing it in 2011

(4)

Dependent variable

(5)

(6)

Dependent variable

Personal network size

$\begin{array}{cc}-0.00211 & -0.0470 \\ (0.0627) & (0.0533) \\ & 0.00947 * * \\ & (0.00459)\end{array}$

--- × personal network clustering

(0.00459)

Personal network size with reliable partners

$$
\begin{array}{cc}
-0.0394 & -0.310 \\
(0.0553) & (0.196) \\
& 0.0238^{*} \\
& (0.0143)
\end{array}
$$

Personal network size based on frequent meetings

$$
\begin{array}{cc}
0.0191 & -0.143 \\
(0.0350) & (0.0990) \\
& 0.0142 * \\
& (0.00760)
\end{array}
$$

--- × personal network clustering

Knowing any extension agent

$\begin{array}{cc}0.598 & -0.131 \\ (0.839) & (0.931)\end{array}$

Knowing any reliable agent

$0.678 * * \quad 0.761^{*}$

(0.344) (0.394)

Knowing \& meeting any agent

Years of schooling

Log of cultivated land

\subsection{8}

(0.0261)

0.0567

(0.0381)

$-0.00892$

$-0.104$

(0.0924)

(0.119)

$0.280 *$

0.141

(0.162)

(0.195)

Distance from farmer training center

0.0122

$-0.0202$

(0.0301)

(0.0366)

Observations

76

76

0.313

0.850

0.0161

(0.0188)

$-0.0658$

(0.104)

0.161

(0.155)

0.00345

(0.0338)

\begin{tabular}{ccc} 
& 0.203 & 0.446 \\
$0.0446 * * *$ & $0.0306^{*}$ & $0.0496 * * *$ \\
$(0.0172)$ & $(0.0172)$ & $(0.0154)$ \\
-0.145 & -0.0573 & -0.124 \\
$(0.122)$ & $(0.0935)$ & $(0.0957)$ \\
0.0979 & 0.271 & $0.297 *$ \\
$(0.175)$ & $(0.165)$ & $(0.171)$ \\
-0.00717 & 0.0295 & -0.00111 \\
$(0.0420)$ & $(0.0299)$ & $(0.0381)$ \\
\hline 76 & 76 & 76 \\
0.634 & 0.297 & 0.647
\end{tabular}

Notes: The results are based on GMM estimations using a linear probability model. Standard errors are in parentheses. ***, $* *$, and * signify statistical significance at the 1, 5, and 10\% levels, respectively. Dummies for ethnicity, religion, and villages are included but not reported for brevity. The personal network size indicates is the number of instances where the household knows at least one individual whose name appears among the first 14 on the list, whereas the personal network clustering represents the number of pairs who know one another among the 14 randomly selected pairs of household acquaintances. 
Table 6: Determinants of Adoption of Compost

\section{(1)}

(2)

(3)

(4)

(5)

(6)

Using compost in 2012

Dependent variable
Personal network size

--- $\times$ personal network clustering

Personal network size with reliable partners

--- $\times$ personal network clustering

Personal network size based on frequent meetings

--- $\times$ personal network clustering
$-0.0540 \quad-0.0516$
(0.0419) (0.0500)
$-0.000210$
$(0.00331)$

$\begin{array}{cc}-0.0216 & -0.0291 \\ (0.0426) & (0.139) \\ & 0.000546 \\ & (0.0103)\end{array}$

(0.0103)

Knowing any extension agent

$0.607 \quad 0.593$

(1.215) (1.210)

Knowing any reliable agent

$-0.293 \quad-0.279$

(0.402) (0.444)

Knowing \& meeting any agent

Years of schooling

Log of cultivated land

0.0273

0.0275

$-0.397$

(0.463) (0.407)

0.00251

$(0.0332)$

(0.0176)

(0.0167)

0.0194

0.0202

$-0.0723$

$-0.0716$

$-0.0675$

$-0.0668$

(0.0148)

(0.0146)

(0.0947)

(0.0943)

$(0.0966)$

(0.0966)

0.0405

0.0167

0.00485

0.00584

$-0.0111$

$-0.0139$

(0.127)

(0.154)

(0.159)

$0.0511 * \quad 0.0515 *$

(0.119)

(0.137)

$-0.0567$

(0.118)

Distance from farmer training center

(0.0300)

Observations

111

(0.0309)

111

0.0476

(0.120)

$-0.0749$

(0.122)

(0.0290)

(0.0295)

$0.710 \quad 0.701$

0.632

111
(0.0448)

$P$ value of Hansen $J$ statistic

Notes: The results are based on GMM estimations using a linear probability model. Standard errors are in parentheses. ***, $* *$, and * signify statistical significance at the 1, 5, and 10\% levels, respectively. Dummies for ethnicity, religion, and villages are included but not reported for brevity. The personal network size indicates the is the number of instances where the household knows at least one individual whose name appears among the first 14 on the list, whereas the personal network clustering represents the number of pairs who know one another among the 14 randomly selected pairs of household acquaintances. 
Table 7: Determinants of the Number of Information Sources

Dependent variable: Number of persons from whom the household received the same information as from the most influential source

\begin{tabular}{|c|c|c|}
\hline & $\begin{array}{c}\text { (1) } \\
\text { Row planting }\end{array}$ & $\begin{array}{c}(2) \\
\text { Compost }\end{array}$ \\
\hline Personal network size $\times$ personal network clustering & $\begin{array}{c}0.0369 \\
(0.0333)\end{array}$ & $\begin{array}{c}0.0506^{* *} \\
(0.0207)\end{array}$ \\
\hline Years of schooling & $\begin{array}{c}0.145^{*} \\
(0.0782)\end{array}$ & $\begin{array}{l}0.149 * * \\
(0.0721)\end{array}$ \\
\hline Log of cultivated land & $\begin{array}{l}-0.518 \\
(1.034)\end{array}$ & $\begin{array}{c}0.325 \\
(0.537)\end{array}$ \\
\hline Myopia & $\begin{array}{l}-0.460 \\
(1.114)\end{array}$ & $\begin{array}{c}0.405 \\
(0.756)\end{array}$ \\
\hline Distance from farmer training center & $\begin{array}{l}-0.387^{*} \\
(0.205) \\
\end{array}$ & $\begin{array}{l}-0.0506 \\
(0.152)\end{array}$ \\
\hline $\begin{array}{l}\text { Observations } \\
P \text { value of Hansen } J \text { statistic }\end{array}$ & $\begin{array}{c}119 \\
0.750\end{array}$ & $\begin{array}{c}109 \\
0.988\end{array}$ \\
\hline
\end{tabular}

Notes: The results are based on GMM estimations using a linear probability model. Standard errors are in parentheses. ***, $* *$, and $*$ signify statistical significance at the 1,5 , and $10 \%$ levels, respectively. Dummies for ethnicity, religion, and villages are included but not reported for brevity. The personal network size indicates is the number of instances where the household knows at least one individual whose name appears among the first 14 on the list, whereas the personal network clustering represents the number of pairs who know one another among the 14 randomly selected pairs of household acquaintances. 


\section{References}

Bandiera O., Rasul I., 2006. Social networks and technology adoption in northern Mozambique. Economic Journal. 116, 869-902.

Blundell R., Bond S., 1998. Initial conditions and moment restrictions in dynamic panel data models. Journal of Econometrics. 87, 115-43.

Burt R.S., 1992. Structural Holes. Harvard University Press, Boston.

Caselli F., 2005. Accounting for cross-country income differences, in: Aghion P., Durlauf S.N. (Eds), Handbook of economic growth. North Holland: Amsterdam.

Centola D., 2010. The spread of behavior in an online social network experiment. Science. 329, 1194-97.

Conley T.G., Udry C., 2010. Learning about a new technology: Pineapple in Ghana. American Economic Review. 100, 35-69.

Duflo E., Kremer M., Robinson J., 2004. Understanding technology adoption: Fertilizer in Western Kenya, preliminary results from field experiments. Unpublished manuscript, Massachusetts Institute of Technology, available at http://sticerd.lse.ac.uk/dps/bpde2004/duflopaper.pdf.

Foster A.D., Rosenzweig M.R., 1995. Learning by doing and learning from others: Human capital and technical change in agriculture. Journal of Political Economy. 103, 1176-209.

Foster A.D., Rosenzweig M.R., 2010. Microeconomics of technology adoption. Annual Review of Economics. 2, 395-424.

Granovetter M.S., 1973. The strength of weak ties. American Journal of Sociology. 1360-80.

Hansen L.P., 1982. Large sample properties of generalized method of moment estimators. Econometrica. 50, 1029-54.

International Telecommunication Union, 2013. World Telecommunication/ICT Indicators Database. Available at http://www.itu.int/en/ITU-D/Statistics/Documents/statistics/2012/Mobile_cellular_2000-2011.xls.

Manski, Charles F., 1993. Identification of Endogenous Social Effects: The Reflection Problem." The Review of Economic Studies. 60, 531-42.

McCarty C., Bernard H.R., Killworth P.D., Shelley G.A., Johnsen E.C., 1997. Eliciting representative samples of personal networks. Social Networks. 19, 303-23.

Munshi K., 2004. Social learning in a heterogeneous population: Technology diffusion in the Indian green revolution. Journal of Development Economics. 73, 185-213.

Newey W.K., 1987. Efficient estimation of limited dependent variable models with endogenous explanatory variables. Journal of Econometrics. 36, 231-50.

Pender J., Gebremedhin B., 2006. Land management, crop production, and household income in the highlands of Tigray, Northern Ethiopia: An econometric analysis, in: Pender J., Place F., Ehui S. (Eds), Strategies for sustainable land management in the east african highlands. International Food Policy Research Institute: Washington D.C.

Pretty J.A., Noble D.N., Bossio D., Dixon J., Hine R.E., Penningdevries F.W.T., Morison J.I.L., 2006. Resource-conserving agriculture increases yields in developing countries. Environmental Science \& Technology. 40, 1114-19

Rogers E.M., 1995. Diffusion of Innovations. Free Press.

Romer P.M., 1990. Endogenous technological change. Journal of Political Economy. 98, S71-102.

Rost K., 2011. The strength of strong ties in the creation of innovation. Research Policy. 40, 588-604.

Tiwana A., 2008. Do bridging ties complement strong ties? An empirical examination of alliance 
ambidexterity. Strategic Management Journal. 29, 251-72.

Watts D.J., Strogatz S.H., 1998. Collective dynamics of 'small-world' networks. Nature. 393, 440-42. 